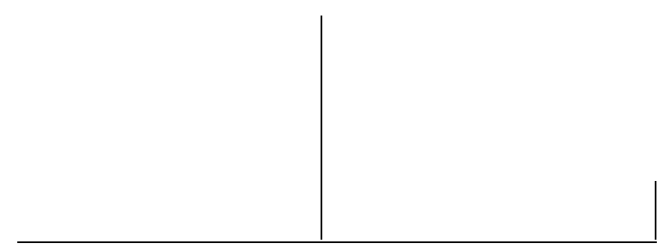

Rev. Latinoam. Psicopat. Fund., VIII, 2, 303-321

\title{
Responsabilidade e Reforma Psiquiátrica Brasileira: sobre a relação entre saberes e políticas no campo da saúde mental*
}

\author{
Martinho B. B. Silva
}

Este texto visa delinear a relação entre saberes e políticas no campo da saúde mental. Discursos como a "tomada de responsabilidade do serviço pelo território", o "aumento da responsabilidade do profissional pelo processo de trabalho" e a "possibilidade do sujeito advir como responsável por sua própria condição" são veiculados por diferentes disciplinas, como a psicanálise, a saúde pública e a análise institucional. Esses discursos se conjugam a um momento sócio-histórico particular no Brasil. Acredita-se que a descentralização, preconizada pelas políticas públicas de saúde, desencadeia um processo de "transferência de responsabilidades para unidades locais com concentração de poder em nível central".

Palavras-chave: Responsabilidade, saúde mental, formação profissional, políticas públicas de saúde

* Este texto foi apresentado na Reunião Anual da Associação Brasileira de Psicologia Social (ABRAPSO), de outubro de 2003, em Porto Alegre-RS, como comunicação oral com o título "Responsabilidade e Reforma Psiquiátrica Brasileira”.

Este tema foi desenvolvido no primeiro capítulo de minha dissertação de mestrado defendida em abril de 2004 no IMS-UERJ, com o título "Responsabilidade e Reforma Psiquiátrica Brasileira: sobre a produção de engajamento, implicação e vínculo nas práticas de atenção psicossocial”, sob orientação do Prof. Dr. Sérgio Carrara, co-orientação da Prof ${ }^{a} D^{\text {ra }}$ Jane Russo, e financiamento da Fundação de Amparo à Pesquisa do Estado do Rio de Janeiro (FAPERJ). 
Este texto trata de um dos dilemas do movimento pela Reforma Psiquiátrica Brasileira: a responsabilidade dos atores e instâncias sociais envolvidos no cuidado, principalmente daqueles ligados aos Centros de Atenção Psicossocial (CAPS).

Em processo desde o final da década de 1970, a Reforma Psiquiátrica tem contribuído para a implementação de uma nova política pública de assistência aos pacientes psiquiátricos e a construção de tecnologias de cuidado inovadoras. A substituição progressiva do hospital psiquiátrico por serviços regionalizados é um de seus aspectos. Também a busca de uma forma de cuidado que, ao mesmo tempo, diminua o sofrimento humano, produza autonomia e ampliação dos laços sociais - ao invés de segregação, violência e abandono - é outro aspecto, do mesmo modo que a luta contra a exclusão social e o estigma de incapacidade e periculosidade associado à doença mental. Nesse projeto de mudança da política governamental, da clínica e da representação social em torno da loucura, um dos desafios diz respeito à parcela de encargo, implicação ou engajamento tanto dos profissionais e serviços, como dos vizinhos, familiares e usuários.

Esse terreno, de uma certa produção de responsáveis pelo cuidado, pode ser instigante para investigar a dimensão tutelar das práticas em saúde mental, entendendo-as como articuladas a modalidades de gestão de populações e tecnologias de poder em ação sobre indivíduos. Diferentemente de uma perspectiva que procura avaliar os graus ou concepções de responsabilidade em jogo no campo da saúde mental, a pesquisa que desenvolvi no mestrado visou o processo responsabilização de atores sociais no cotidiano assistencial, de modo que a "clínica ampliada" (Goldberg, 1996), profundamente tematizada ao longo da reforma, possa ser desnaturalizada e problematizada em sua dimensão "psi" e terapêutica. Aproxima-se, portanto, dos trabalhos de Castel (1978) relativos à dimensão administrativa da prática psiquiátrica e ao aggiornamento do dispositivo psiquiátrico operado pelas iniciativas de reforma no pós-guerra. Este trabalho também considera as contribuições de Lima (1995) e Vianna (2002) sobre as tecnologias de poder colocadas em ação nas instâncias da administração pública estatal, na medida em que 


\section{SAÚDE MENTAL}

algumas delas estão comprometidas com a gestão de populações tuteláveis do ponto de vista jurídico (índios, menores e também, por que não, os loucos) e com a sua fixação a um determinado território.

Esse texto procura situar o tema da responsabilidade no conjunto de saberes do campo da saúde mental e contextualizá-lo no interior das políticas governamentais. O objetivo geral é apresentar a responsabilidade como noção com efeitos sobre a formação dos profissionais de saúde mental, sem deixar de destacar a relação que essa prática discursiva estabelece com as políticas de saúde do Estado brasileiro.

Assim, pretendo apontar as diferentes perspectivas teóricas que contribuem para a formulação de uma nova prática assistencial no contexto da reforma psiquiátrica brasileira, algumas enfatizando a "responsabilidade do sujeito pelo próprio sintoma", outras a "responsabilidade da equipe pelo processo de trabalho" e, ainda, a "responsabilidade do serviço pelo território". Também será necessário apontar que esse apelo à responsabilidade, que convoca usuários, técnicos e serviços a uma nova postura diante das adversidades do processo de desinstitucionalização da assistência psiquiátrica, acontece em meio a um cenário político-econômico de desresponsabilização - progressiva, por sinal - do Estado brasileiro face às necessidades de atenção em saúde da população, ou seja, a uma política social neoliberal. ${ }^{1}$

Encarregar, implicar e engajar: encargos e recursos do serviço, do profissional e do usuário

Mas do que se trata a reforma psiquiátrica brasileira? Uma das definições possíveis desse movimento que envolve desospitalização, atendimento na comunidade e produção de autonomia é aquela que entende a reforma como:

... um processo histórico de formulação crítica e prática, que tem como objetivos e estratégias o questionamento e elaboração de propostas de transformação do modelo clássico e do paradigma da psiquiatria. No Brasil, a reforma psiquiátrica é um processo que surge mais concreta e, principalmente, a partir da conjuntura

1. Esse não parece ser um fenômeno local, já que em uma publicação recente, representantes do governo de diferentes países da América Latina apontaram a mesma retração do Estado face às políticas sociais como desafio para o movimento pela reforma psiquiátrica. Ver parte II "Políticas públicas, neoliberalismo e movimento antimanicomial na América Latina”, da coletânea organizada por Maria Fernandes, Ianni Scarcelli e Eliane Costa (1999). 


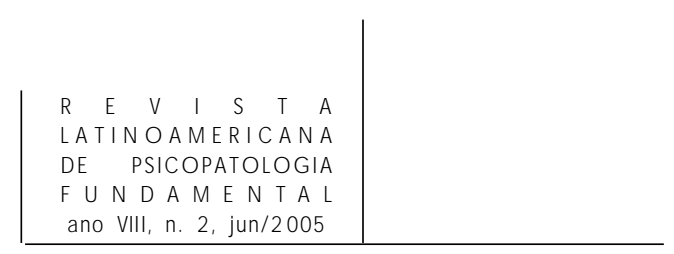

da redemocratização, em fins da década de 1970. Tem como fundamentos não apenas uma crítica conjuntural ao subsistema nacional de saúde mental, mas também - e principalmente - uma crítica estrutural ao saber e às instituições psiquiátricas clássicas, dentro de toda a movimentação político-social que caracteriza a conjuntura de redemocratização. (Amarante, 1995, p. 87)

A reforma também se apresenta como uma política pública de saúde mental, tem uma dimensão político-institucional, com diretrizes no sentido da modificação da assistência psiquiátrica em vigor no país. Ela tem comprometimento com a instauração do Sistema Único de Saúde (SUS) e com a política pública de saúde, procurando implementar um projeto de universalidade, eqüidade e integralidade da assistência pública, com descentralização da gestão e privilegiando o atendimento na comunidade. Essa política está articulada a um projeto de prática assistencial, a uma formulação de clínica, orientando uma mudança também nas modalidades de cuidado em saúde mental:

Situada no plano das políticas públicas, a reforma psiquiátrica mira o coletivo. Seu objeto é a população, e a demanda potencial é definida através de ferramentas epidemiológicas. O objeto da clínica, por sua vez, é o sujeito singular, o projeto terapêutico individualizado, a relação transferencial única e não generalizável. Se a reforma prioriza um segmento crucial da demanda, ao qual vem sendo destinado até hoje o périplo funesto das longas internações e da tutela sem nuanças, sua intervenção particular se dá através das exigências que faz para a clínica: a autonomia possível, a cidadania do louco e o investimento na rede e no território. Só resta, portanto, um caminho possível entre a política e a clínica: a clínica da reforma. (Delgado, 2001, p. 153-4)

Desta maneira, a reforma - sob uma perspectiva mais ampla - se organiza de maneira a instalar um processo de desinstitucionalização da doença mental, do conjunto de aparatos jurídicos, administrativos e culturais - entre outros organizados no sentido de produzir a loucura como doença mental e situar o louco como incapaz e perigoso (Bezerra Jr., 1994, Rotelli et. al, 1990). Mas, de modo mais específico, envolve a formulação de diretrizes, por parte de agentes do Estado - os "gestores" - no sentido da implantação de um processo de desospitalização e territorialização da assistência: delegação a unidades locais da responsabilidade pelas necessidades em saúde mental de uma determinada população. É nesse sentido que "Fala-se de reforma há muito tempo...”, mas “... sua inflexão nas políticas públicas brasileiras se deu a partir de 1989-90” (Delgado, 2001, p.153).

Em algum momento desses mais de vinte anos de reforma psiquiátrica no Brasil um discurso começou a aparecer com veemência, principalmente diante dos impasses instalados nos serviços territoriais: "quem é que pode ser responsabilizar por isso?", ou ainda "será que ele não tem que estar mais implicado nesse 


\section{SAÚDE MENTAL}

ano VIII, n. 2, jun $/ 2005$

tratamento?”, e por que não "pode ele responder pelos próprios atos no momento?”. Responsabilidade - termo eminentemente jurídico e administrativo, assim como de cunho fortemente moral - parece ter se tornado uma espécie de palavra de ordem nos espaços assistenciais, acadêmicos e institucionais no campo da saúde mental contemporâneo.

Acompanhando a produção teórica gerada nesse campo, em especial ao longo da década de 1990, percebe-se que cidadania já ocupou esse lugar anteriormente. Para alguns, o debate constante sobre o percurso sociohistórico dessa categoria parece tê-la desgastado com o tempo (Leal, 1999, p. 161-2). Se em outro momento da reforma psiquiátrica no nosso país a luta "por uma sociedade sem manicômios" e pela "cidadania do louco" tinha força (Delgado, 1992, p. 17), em tempos do lema "cuidar sim, excluir não" a potência parece estar com a responsabilidade, a implicação e a participação.

Fala-se de uma "tomada de responsabilidade pelo território", ou da "responsabilidade subjetiva para com a própria condição" e também da "implicação e responsabilização social dos atores”, num convite aos serviços, usuários e profissionais a se responsabilizar pela clientela, por sintomas e atitudes, respectivamente.

Por um lado temos as utopias e lemas da década de 1980, recheada de princípios e intenções em nome da liberdade e solidariedade, por outro, os enfrentamentos e impasses da década de 1990, difusora dos limites das tecnologias de cuidado.

Esse deslizamento no acento da Reforma, de cidadania e sociedade para responsabilidade e cuidado, estabelece relações com o quê? Seria uma continuação do debate entre clínicos e políticos (Bezerra Jr., 1992; 1994) em outros termos, ou melhor, seria apontar esse fenômeno como uma complexificação do sujeito cidadão (Russo, 1997), não mais tão racional no sentido de livre e autônomo, mas plenamente e mais do que nunca responsável pelos próprios atos?

Falar de responsabilidade nesse momento também se justifica pela própria reorganização das relações entre família, hospital e Estado que o tratamento prioritário nos serviços comunitários aponta no horizonte. A internação como medida de tratamento prioritária requeria uma responsabilidade - administrativa - minimizada para profissionais e familiares e um ônus maximizado para o Estado, diferente do atendimento na comunidade como tecnologia de cuidado privilegiada. Nessa "nova" modalidade, a relação entre técnicos e familiares se intensifica na divisão cotidiana de cuidado e, principalmente, de responsabilidades pela gestão emocional, relacional e também econômica do usuário; o Estado redireciona seus gastos às políticas públicas locais, de atendimento às populações e áreas carentes de serviços de saúde, ao mesmo tempo em que enxuga seus investimentos em políticas sociais. 


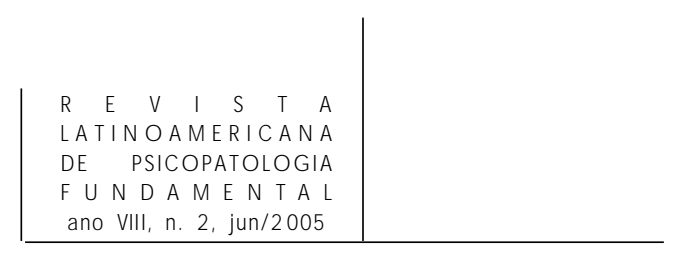

Castel (1978) nos indica os mesmos personagens e um dinamismo semelhante ao nosso cenário atual, ao tratar da psiquiatria de setor francesa, na década de 1970. Enfatiza as funções administrativas e políticas da atividade psiquiátrica, segundo ele, mais relevantes para analisar seus efeitos sociais que as finalidades terapêuticas. É essa idéia da psiquiatria como saber administrativo que faz da responsabilidade uma questão relevante, na medida em que a gestão dos usuários se destaca justamente nessa reordenação das instituições sociais de amparo ao louco: "quem (familiar, técnico) se responsabiliza por quem (louco) ou o que (cuidado; benefício do INSS...)?”, é uma questão presente e insistente nos serviços extra-hospitalares implantados a partir do processo reformista.

A responsabilidade tem sido não só um discurso do campo da saúde mental, mas também um operador da prática assistencial nos serviços territoriais. A prática dos Centros de Atenção Psicossocial, pelo menos no município do Rio de Janeiro, está orientada pelo acolhimento, vínculo e definição precisa da responsabilidade de cada profissional no atendimento à população (IFB, 2003). O encargo pelos cuidados em saúde mental não é responsabilidade exclusiva nem das famílias, nem dos profissionais e nem das instâncias públicas de amparo, mas algo que exige distribuição, delegação e negociação de responsabilidade entre esses atores sociais, cada dia mais intensa na medida em que a internação deixa de se tornar o principal recurso assistencial e a convivência passa a ser o principal instrumento de terapêutica.

Esse momento histórico evidencia uma certa economia na dinâmica do cuidado em saúde mental, dá visibilidade aos encargos que a atenção psicossocial envolve. Há quem diga que a atitude do profissional de internar ou encaminhar o usuário de um serviço comunitário de saúde mental nem sempre obedece a uma indicação técnica: trata-se de dar alta a si próprio do tratamento, de uma desresponsabilização do técnico pelo atendimento em um momento de intensa necessidade de cuidado por parte do usuário.

\section{“Tomada de responsabilidade do serviço pelo território": a Reforma Italiana e a organização de serviços}

A Reforma Psiquiátrica Italiana exerceu forte influência sobre a RPb, sendo que uma das suas principais contribuições é o conceito e operador prático designado por "tomada de responsabilidade". O presa in carico dos italianos, a tomada de responsabilidade - por parte dos profissionais de um dado serviço comunitário de saúde - pelas necessidades em saúde mental de uma determinada população adscrita a uma área geográfica, não só contribui para a formulação das 


\section{SAÚDE MENTAL}

ano VIII, n. 2 , jun $/ 2005$

políticas públicas de saúde mental no Brasil (Nicácio, 1994; Delgado, 1999) como também sobre iniciativas mais amplas em saúde pública (Campos, 1992).

Os textos de Rotelli et. al. (1990), Dell'Aqua e Mezzina (1991) e Delgado (1999) serão nossas bússolas nesta apresentação desses componentes do discurso da responsabilidade no campo da saúde mental.

Os serviços, segundo Rotelli et. al (1990, p. 37), têm a responsabilidade de responder à totalidade das necessidades de saúde mental de uma população determinada. Essa é uma das diretrizes que contribuíram para a organização dos serviços de saúde mental da cidade de Trieste, segundo o autor a experiência italiana mais conhecida no nível internacional e que orientou o processo global da transformação institucional na Itália. Essa diretriz tem em vista o processo de desinstitucionalização, procurando liberar o sistema de atenção psiquiátrica da internação, construindo novos serviços inteiramente substitutivos aos hospitais psiquiátricos.

Tomar para si a responsabilidade” pelo cuidado parece ser uma estratégia em relação à tendência de cristalização das práticas dos especialistas, uma tentativa de fazer com que os profissionais organizem-se de um modo que responda mais às necessidades da população e menos às necessidades de legitimação corporativa das próprias técnicas e teorias. (Rotelli, 1990, p. 37)

Enfim, é uma tecnologia de gestão, de organização da equipe em relação ao processo de trabalho. Atende ao quê, à substituição da internação pelo atendimento na comunidade?

Esse modo de organização dos serviços parte de uma constatação: o fracasso de tentativas reformistas em outros países diante do desafio do mandato social de controle da psiquiatria. Esse mandato social, que inclui controle, exclusão e violência, é costumeiramente representado pelo asilo e pela instituição da incapacidade e da periculosidade do doente mental, sendo que a internação e o abandono são suas figuras na prática assistencial.

Segundo Rotelli (1990, p. 19), a reforma em outros países acabou se transformando em um programa de racionalização financeira e administrativa, sinônimo de redução de leitos hospitalares, foi praticada como desospitalização, política de altas hospitalares, redução mais ou menos gradual do número de leitos; com a intenção de renovar a capacidade terapêutica da psiquiatria, liberando-a das suas funções arcaicas de controle social, coação e segregação, a reforma revelouse coerente com as orientações neoliberais e conservadoras de redimensionamento do próprio "Estado de bem-estar social". A reforma italiana, deste modo, construiu uma nova tecnologia de gestão balizada pela responsabilidade territorial, no sentido de ultrapassar esses obstáculos e superar os problemas de outras experiências de reforma. 


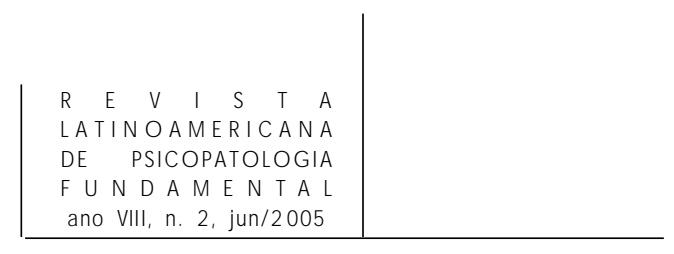

A tomada de responsabilidade é uma resposta ao abandono e uma forma de substituir a internação por outras formas de cuidado. Essa diretriz se acopla a duas outras, como já indiquei anteriormente: mudar as formas de administrar os recursos e complexificar a prática profissional. Veremos a seguir que essas diretrizes são desdobramentos da primeira: a tomada de responsabilidade do serviço pelo território envolve chamar à responsabilidade outras instâncias públicas de amparo, como também oferecer atenção integral.

Segundo Rotelli (1990), houve muita atenção para com os efeitos de capilarização do controle social produzido pelos serviços "psi” na comunidade, enquanto se deixava de lado o abandono gerado pelos mesmos especialismos:

As análises sociológicas e sociopsiquiátrica têm insistido em apontar os riscos presentes nesta difusão e especialização dos serviços psiquiátricos na comunidade: psiquiatrização dos problemas sociais e difusão capilar dos mecanismos de controle social na comunidade (...) Mas estas preocupações deixaram de lado outros efeitos complementares a estes, ou seja, os efeitos de seleção, de falta de resposta aos problemas e sofrimentos das pessoas, de abandono. (p. 22; grifos meus)

A atuação profissional "especialística” tem efeitos de abandono e desresponsabilização pelo cuidado e assistência em saúde mental, indicando uma “profissionalidade” restrita em relação às necessidades da população:

O elevado nível de especialização e de refinamento das técnicas de intervenção tem como conseqüência uma correspondente elevação da seleção de pacientes assumidos (...) esta forma especialista e seletiva de funcionar dos serviços psiquiátricos faz com que as pessoas sejam separadas, “despejadas”, jogadas de um lado para outro entre competências diferentes e definitivamente não sejam de responsabilidade de ninguém e sim abandonadas a si mesmas. (p. 22; grifos meus)

A problemática do abandono tem na responsabilidade integral pelo cuidado em saúde mental uma possível saída, apontando para a incrementação do repertório de técnicas do trabalhador em saúde mental. É o que sugere o autor, tendo em vista sua crítica:

Este é então outro aspecto de trabalho terapêutico entendido como "tomar encargo" [presa in carico foi traduzido por "tomar encargo"; cabe ressaltar que esta expressão se constitui numa premissa fundamental na organização dos serviços territoriais e significa o "fazer-se responsável”, isto é, a impossibilidade de delegar a uma outra estrutura a assistência à população da região de referência], de cuidar de uma pessoa: é desenvolvido de tal modo a evitar o abandono do paciente a si mesmo... (p. 34; grifos meus) 


\section{SAÚDE MENTAL}

ano VIII, n. 2, jun $/ 2005$

A tomada de responsabilidade do serviço pelo território, deste modo, também é fazer-se responsável pela atenção integral ao invés de delegar a outros especialistas o cuidado em saúde mental, e assim "complexifica a profissionalidade" dos operadores. Em vez de trabalhar exclusivamente com as competências e possibilidades exclusivas dos saberes médicos e "psi", cabe ao profissional de saúde mental responsabilizar outras instâncias administrativas pelo cuidado em saúde mental (p. 39).

Tomar o encargo pelo cuidado integral da população, chamar à responsabilidade outras instâncias, complexificar a profissionalidade (outros encargos e ações no atendimento) e modificar a gestão dos recursos assistenciais tem estreita relação com a tomada de responsabilidade pelo território; são diferentes componentes dessa diretriz.

Dell’Aqua e Mezzina (1991) apontam a responsabilidade como uma dimensão da atividade profissional em um dos momentos mais complexos do atendimento psiquiátrico: a crise. Juntamente com o "contato", a tomada de responsabilidade é um elemento preciso nesse momento de intervenção na crise. A idéia que norteia mais uma das contribuições da Reforma Italiana à Reforma no Brasil é que a internação responde à doença enquanto a tomada de responsabilidade pelo cuidado em saúde mental responde às diferentes formas e momentos da existência do usuário:

Não apenas na situação de crise, como também na relação global (com respeito aos momentos e às formas da existência que sofre), a "tomada de responsabilidade" configura uma nova modalidade de relação institucional, que se baseia propriamente na assunção de responsabilidade. Em outras palavras, o Centro de Saúde Mental deve assumir a função de referencial ativo às demandas relativas a situações de miséria, de distúrbio e de conflito (...) A prática cotidiana da "presença" produziu uma real penetração do serviço no território e permitiu aos cidadãos a aquisição de um útil conhecimento das suas funções. (p. 62; grifos meus)

Assim, aos sentidos e às dimensões da responsabilidade apontados por Rotelli (1990) acrescenta-se esse desdobramento, onde responsabilizar-se pelo território inclui também imiscuir-se no cotidiano da existência e do sofrimento das pessoas; o serviço deve colocar-se como referência para situações variadas de conflito e estar presente nos diferentes momentos da vida do usuário.

Delgado (1999, p. 118-9) resume a problemática da tomada de responsabilidade no contexto da reforma psiquiátrica brasileira, apontando as diferentes orientações da implantação de serviços comunitários de saúde mental em cidades brasileiras: os CAPS do Rio de Janeiro e os NAPS de Santos. Embora o autor trabalhe, nesse momento mais comparativo, com um sentido mais restrito - responsabilidade como tomada de responsabilidade pelas necessidades em saúde mental 


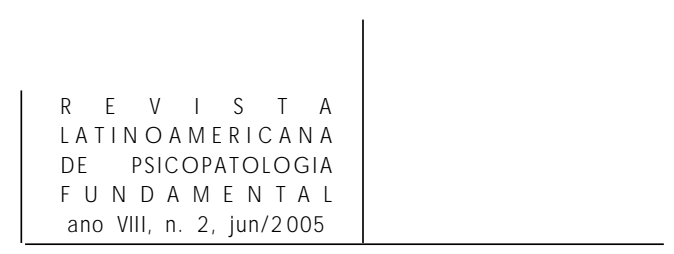

de uma população adscrita a uma área geográfica - em outros momentos do texto apresenta sua perspectiva sobre território - não tanto sobre responsabilidade como "cidade subjetiva", "locus de conflito e luta" e "singularidade espacial". Assim, no que tange ao nosso assunto, cabe a longa citação do autor:

Situemos a questão: um CAPS tem capacidade limitada (cerca de quarenta a cinqüenta pacientes em atendimento diário, intensivo, e em torno de trezentos a quatrocentos matriculados, isto é, atendidos em graus muito diversos de intensidade do cuidado); já o NAPS define sua capacidade pela meta a atingir de cobertura de uma população adscrita (território), e pelo pressuposto ético da tomada de responsabilidade. Para que o contexto urbano possa tornar-se objeto de nossa análise, ou seja, para dar-lhe sentido na organização de serviços e na clínica, é preciso superar o modelo da demanda espontânea (que é coerente na clínica de consultórios e serviços privados), e tomar as noções de cobertura assistencial e referência domiciliar como indispensáveis. Assim, importa menos que o CAPS de Campo Grande defina sua capacidade (...) e mais o fato de que aquele seja o serviço territorial de referência para a população de tal bairro da cidade do Rio de Janeiro. (Delgado, 1999, p. 113-4; grifos do autor)

A tomada de responsabilidade pelo território é uma diretriz da reforma psiquiátrica brasileira, ligada à substituição da lógica dos serviços privados demanda espontânea e capacidade - por uma lógica dos serviços públicos cobertura assistencial e referência domiciliar - talvez até, como veremos ao final, uma lógica estatal.

Essa diretriz fica muito clara na Portaria 336, de fevereiro de 2002, sobre o funcionamento dos CAPS. Os serviços adquirem atribuições gerenciais e administrativas sobre a rede de saúde mental de uma determinada área geográfica. Cabe a eles "responsabilizar-se, sob coordenação do gestor local, pela organização da demanda e da rede de cuidados em saúde mental no âmbito do seu território" e "possuir capacidade técnica para desempenhar o papel de regulador da porta de entrada da rede assistencial no âmbito do seu território...”.

Tais atribuições do serviço estão intrincadas às possibilidades do profissional assumir encargos e funções diferenciadas, como veremos a seguir.

\section{“Aumento do grau de responsabilidade do profissional no processo de trabalho em saúde": a análise institucional e a gestão de recursos humanos}

A idéia de que a prática assistencial está articulada a uma gestão e organização dos serviços guia a formulação da responsabilidade como aspecto do processo de trabalho da equipe de saúde mental. A indissociabilidade entre clínica 


\section{SAÚDE MENTAL}

ano VIII, n. 2, jun/ 2005

e administração, a análise tanto do usuário quanto do profissional, a implicação de todos os atores envolvidos na assistência são premissas dessa concepção de responsabilidade em muito influenciada pelas contribuições da análise institucional.

Braga Campos (1992a; 1992b) e Furtado (2001) são alguns dos autores que apontam na responsabilidade do profissional pelo processo de trabalho um fator de incremento de qualidade nas práticas em saúde mental, como também nas práticas de saúde de um modo geral. Tratando da experiência de desinstitucionalização do hospício "Cândido Ferreira" em Campinas, SP, um dos autores assim apresenta essa concepção:

O planejamento e a gestão democrática só ganham sentido se possibilitarem e viabilizarem o desenvolvimento do potencial das equipes de profissionais, de fato criando um sistema de trabalho conjunto, a responsabilidade coletiva por todos os atos praticados e ainda estimulando a indignação ante os limites de toda ordem que dificultam a promoção da cidadania dos usuários de saúde mental. (Braga Campos, 1992a, p. 60; grifos meus)

É como se o modo de administração de recursos humanos, fortemente ligado às formulações da análise institucional, apontasse na responsabilidade, implicação e participação dos profissionais, uma linha de fuga à inércia e burocratização das instituições de saúde. O que se procura produzir é o comprometimento e engajamento do profissional no projeto de desinstitucionalização. Nessa linha de entendimento, esta autora afirma:

Ousar pensar o fim da Administração tradicional. Do taylorismo. A equipe seria coordenada, articulada a diretrizes gerais e às iniciativas de outras equipes congêneres. Não teria seus atos normatizados, não seria dirigida. Cada conjunto de trabalhadores, em um serviço, deveria responder aos problemas de sua área (...) Este estilo de gestão pressupõe uma combinação de progressiva autonomia com responsabilidades e compromissos crescentes. (Braga Campos, 1992b, p. 50; grifos meus)

Furtado (2001) também remete suas reflexões acerca da importância da responsabilização do profissional nas práticas em saúde mental à experiência assistencial em Campinas, SP, tratando de um dispositivo residencial terapêutico. Tanto a responsabilidade como o vínculo do profissional para com o processo de trabalho e o usuário foram determinantes, segundo o autor, na mudança do modelo assistencial asilar. O profissional se torna referência de um conjunto de usuários e responsável pela gestão dos cuidados necessários à sua saúde mental:

O profissional, em seu papel de referência, não é responsável pela execução de todas as atividades previstas no projeto terapêutico, mas deve estar ciente e acompanhar, ainda que à distância, a evolução do paciente no curso das atividades (...) O que caracteriza o papel de referência é o fato de um 


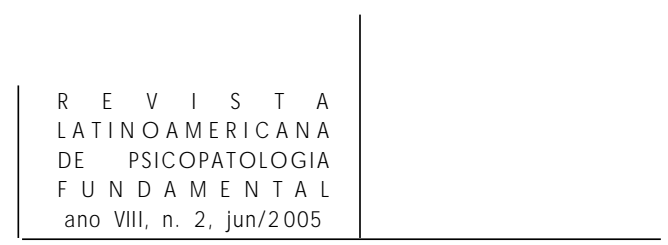

profissional tomar para si o encargo de planejar, acompanhar e avaliar o conjunto de ações terapêuticas que deverão potencializar o processo de reabilitação psicossocial daquele paciente cronificado. Temos a expectativa de que a responsabilização e o vínculo sejam uma das decorrências dessa forma de trabalho". (p. 45; grifos meus)

Anteriormente já vislumbramos que a responsabilização do serviço pelas necessidades de saúde mental de uma população adscrita a uma determinada área geográfica foi uma das diretrizes da reformulação da assistência psiquiátrica no Brasil, onde um serviço local de saúde mental tornava-se responsável por uma população. A esta diretriz estavam correlacionadas outras responsabilidades, como a de ativar os recursos de outras instituições que possam cooperar com o cuidado em saúde mental e de tomar em consideração a existência global do paciente psiquiátrico como horizonte de ação, ou seja, uma responsabilização gradativa dos atores envolvidos na assistência psiquiátrica.

Nesse momento, percebemos que também a equipe de trabalho nos serviços de saúde mental adquire mais encargos, não a responsabilidade de fazer tudo, mas aquela de a tudo administrar, a partir de uma unidade: o indivíduo em tratamento. A responsabilidade do profissional pelo processo de trabalho, como vimos, é mais um elemento desse processo de responsabilização dos atores sociais em vigor no movimento pela reforma psiquiátrica brasileira.

Percebe-se também que a responsabilização desse ator social envolve vincular e tornar-se referência para o paciente psiquiátrico. Assim como o serviço deve se tornar referência de atendimento em saúde mental para uma determinada população, o profissional deve se tornar referência de atendimento para um conjunto de pacientes. Para tanto, para que essa instância e esse ator social possam assumir esse encargo, exige-se uma "tomada de responsabilidade".

Também o usuário deve "tomar a responsabilidade" por algo, no caso, pela própria condição psíquica. Isso é um elemento extremamente valorado no processo terapêutico, inclusive com psicóticos, como veremos a seguir.

\section{"Fazer o sujeito advir como responsável pela sua condição": a psicanálise lacaniana e a clínica}

O trabalho de Goldberg (1996) acerca da clínica ampliada foi um marco da perspectiva "clínica", ligada principalmente à contribuição da psicanálise nas práticas em saúde mental. Mas muitos outros seguiram essa tendência, acrescentando pontos de vista mais do que questionando ou polemizando. Bezerra Jr. (1994), Leal (1999) e Tenório (2001) são exemplares desta tentativa de unir 


\section{SAÚDE MENTAL}

ano VIII, n. 2 , jun $/ 2005$

“minimização do sofrimento” à "ampliação dos horizontes de relação social”, da constituição de um "cuidado que não produza segregação social” ou da atitude de "recuperar a melhor tradição da psiquiatria" e ao mesmo tempo "introduzir a cidadania como eixo da prática clínica”.

É com o último autor que percebemos mais claramente a idéia de que, nessa clínica reformista, a responsabilização do sujeito (usuário) pelo próprio sintoma tem um lugar fundamental. Esse processo de responsabilização é considerado o próprio processo terapêutico, uma saída da situação de vitimização, de destituição do lugar de sujeito que cabe ao usuário, de descompromisso com o tratamento. A psicanálise lacaniana é um saber que em muito contribui para essa perspectiva da responsabilidade:

Aceita-se com alguma facilidade que a contribuição da psicanálise para a reforma está no fato de ser ela, psicanálise, um conjunto articulado de conceitos e práticas que visam localizar o sujeito no sofrimento de que padece e fazê-lo advir como responsável por sua condição - o que é verdadeiro e orienta o trabalho de qualquer psicanalista que atue como "prático” na reforma. (Tenório, 2001, p. 88; grifos meus)

Em termos mais técnicos, ou seja, no interior da teoria lacaniana das psicoses, essa responsabilização do sujeito se justifica como crítica aos discursos e práticas que tomam parte de um processo de objetalização e coisificação do sujeito. Ou seja, do ponto de vista da psicanálise, responsabilizar o sujeito é um modo de lidar com a loucura diferentemente do direito - que desresponsabiliza o sujeito na figura da inimputabilidade - e da medicina - que para tratar torna-o objeto de uma intervenção - e, ao mesmo tempo, da moral, que o culpabiliza. Segundo Jameguiberry e Moscovich (1997), tanto o discurso médico como o jurídico apontam o mesmo objetivo: liberar o sujeito de toda responsabilidade e, com isso, destituí-lo de seu estatuto de sujeito.

Se para Lacan "De nossa posição de sujeito somos sempre responsáveis" (apud Jameguiberry e Moscovich, 1997, p. 8), na estruturação psicótica, alicerçada na recusa ao significante primordial (forclusão do Nome-do-pai), há uma participação - não intencional, mas inconsciente - fundamental do indivíduo no seu processo de adoecimento. De algum modo, a posição que assumimos diante de situações conflitantes - do ponto de vista libidinal ou desejante encontra alicerce no próprio funcionamento psíquico, o que justificaria um engajamento visceral do sujeito na produção de uma estrutura neurótica, psicótica ou perversa. Inclusive, o destaque da formulação lacaniana é nessa implicação do indivíduo no processo saúde-doença:

Assim, é como se o sujeito pudesse optar, diríamos, por afirmar ou forcluir o significante do Nome-do-pai. Esta eleição fundamental deve considerar-se em 


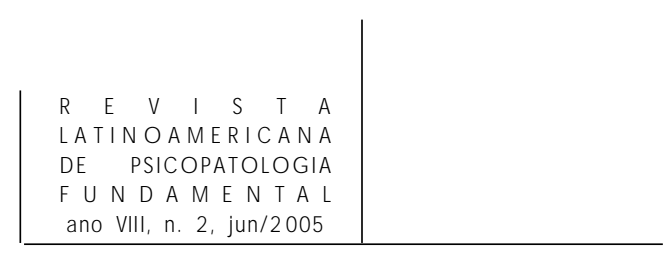

termos de uma responsabilidade, a que implica uma tomada de posição subjetiva (neurose ou psicose), uma decisão do ser. (ibid., p. 9; grifos meus) ${ }^{2}$

Essa idéia de uma responsabilidade do sujeito na produção inconsciente da própria condição de loucura, deste modo, remete à diferença da psicanálise em relação à medicina e ao direito, saberes que também tematizam a responsabilidade individual. Segundo Tenório (2000), a psicanálise inclusive se distancia da configuração de valores individualista que se apresenta na modernidade, sendo a responsabilidade social do sujeito um componente fundamental.

Por um lado temos a responsabilidade individual do sujeito pelo sintoma, na medida em que "Lacan afirma que uma análise deve levar o sujeito a devotar-se à garantia da função do grande Outro, indicando que o sujeito deve assumir sua responsabilidade pelo funcionamento da estrutura simbólica” (p. 117; grifos meus).

Por outro lado, temos a responsabilidade social do sujeito e sua implicação com a sociedade:

Nesta perspectiva, a psicanálise, em vez de lançar o sujeito no individualismo pela assunção de que a totalização é impossível, faz dessa assunção a razão de seu engajamento. Ao entender que também ao grande Outro falta algo que não pode ser preenchido (...) o sujeito é convocado não ao valor da totalização, tampouco ao do individualismo, mas à sua responsabilidade pelo funcionamento social. (p. 132-3; grifos meus)

Serviço, profissional e usuário que devem adquirir responsabilidades de modo que um processo de desinstitucionalização da loucura se efetive. No processo de Reforma Psiquiátrica, diferentes práticas discursivas apontam para a responsabilização dos atores e instâncias sociais pelo cuidado em saúde mental.

\section{“Descentralização de responsabilidades com concentração de recursos”: a implantação das políticas públicas de saúde no contexto do neoliberalismo}

Também os familiares e vizinhos, quando não outros membros da comunidade, participam dessa divisão de encargos pelo cuidado. São as ditas "parcerias" com a comunidade. Além disso, o Estado constantemente é convocado em suas funções de proteção social, como na forma da Lei Federal 10.708, sobre o “Auxílio Reabilitação Psicossocial”, garantindo recursos -

2. A tradução do espanhol para o português é de minha inteira responsabilidade. 


\section{SAÚDE MENTAL}

assistenciais e financeiros - para o processo de saída de pacientes de longa permanência do hospício para a comunidade.

A diretriz constitucional relativa à saúde remete a uma participação da comunidade na gestão, ou seja, ao aumento do poder de decisão da população acerca das políticas públicas de saúde. O controle social pode se dar pela via dos conselhos distritais de saúde. Entretanto, essa diretriz também abre margem para uma maior implicação e engajamento não só na formulação como também na execução das políticas públicas, pela via das "parcerias” com a comunidade e, no campo da saúde mental, com a "rede social" de suporte ao paciente psiquiátrico.

Além disso, o contexto socioeconômico-político em que vivemos essa relação entre Estado e sociedade civil precisa ser tematizado. Já não é nenhuma novidade identificar no processo de globalização a produção de efeitos de minimização das funções e atribuições do Estado. São muitos os autores que se dedicam a descrever e analisar as características do chamado Estado neoliberal e das conseqüências em termos de "enxugamento" das políticas sociais para a população, como por exemplo Offe (1984). Não é preciso apresentar, dentro dos limites deste texto, a complexa discussão acerca do "Estado mínimo”. Entretanto, posso indicar que aquilo que autores da área da saúde pública chamam de "descentralização de responsabilidades com concentração de recursos" é uma das características da política de saúde nas últimas duas décadas.

É no contexto da implantação do SUS e da descentralização da assistência que a idéia da saúde como dever do Estado e direito do cidadão se estabelece como diretriz da política pública de saúde dos anos 1980. Suas características são apresentadas por Luz (2001) de maneira resumida:

O projeto de descentralização em saúde, surgido no Brasil nos anos 1950, é retomado, em termos de política pública, no início da década de 1980, com a crise das políticas sociais do Estado militar autoritário, que teve a duração de duas décadas (...) A novidade, em termos políticos, é que a nova "descentralização" incorpora aos poucos o projeto dos serviços locais de saúde (SILOS), elaborado pelos organismos internacionais da ordem sanitária (OMS/OPS) nos anos 1970. Também cresce a idéia de participação em direção à sociedade civil, aos "usuários" dos serviços, ao invés da idéia de "comunidade", tão cara aos anos 1960. (p. 17; grifos meus)

Embora a idéia de descentralização traga novidades e benefícios sobre os projetos de saúde pública, efetivamente tem esbarrado em uma responsabilização progressiva das unidades locais sem respaldo financeiro para tanto:

... o núcleo central do Estado faz o que pode para se livrar do ônus político, social e econômico que representam saúde e previdência, transferindo para unidades periféricas as funções e, sobretudo, as responsabilidades concernen- 


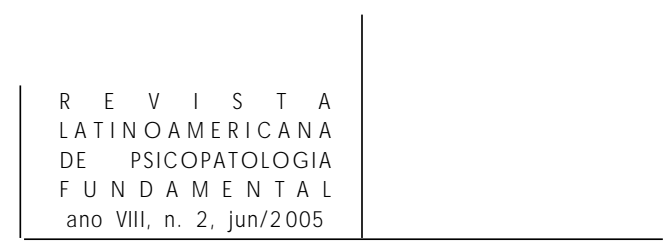

tes a essas funções (...) Desta forma, se quisesse resumir numa formulação clara e simples a política de descentralização da saúde dos governos neoliberais da última década, poderia dizer que esta tem consistido em transferir ("delegar") funções para unidades estatais territorialmente menores (Estados, municípios e locais), no sentido de delas poder "cobrar" responsabilidades referentes às funções delegadas com o menor dispêndio político e financeiro possível. Esta tem sido basicamente a estratégia de descentralização do Estado neoliberal. (ibid., p. 20-1; grifos meus)

Segundo Camargo Jr. (2001, p. 12), essa autora situa histórica, social e politicamente o momento atual da política de saúde, assinalando alguns de seus paradoxos, como a "descentralização de responsabilidades com centralização de recursos financeiros”, num contexto de “ajuste” ao modelo globalizado que jamais se completa.

Deste modo, essa autora apresenta elementos que nos ajudam a contextualizar o fenômeno de responsabilização progressiva que vínhamos notando no discurso do campo da saúde mental. Ele não está articulado unicamente a especificidades das questões que a loucura e a psicose nos colocam, mas também ao contexto historicamente datado das políticas públicas de saúde mental. Uma investigação sobre a reforma psiquiátrica brasileira que tome como pertinente a articulação entre os saberes e as políticas públicas no campo da saúde mental, desta maneira, tem na temática da responsabilidade um elemento relevante.

\section{Referências}

Amarante, Paulo. Loucos pela vida - a trajetória da reforma psiquiátrica no Brasil. Rio de Janeiro: Fiocruz, 1995.

Bezerra Jr., Benilton. Cidadania e loucura: um paradoxo?. In: Bezerra Jr., Benilton e Amarante, Paulo (orgs.). Psiquiatria sem hospício: contribuições ao estudo da reforma psiquiátrica. Rio de Janeiro: Relume-Dumará, 1992. p. 31-40.

De médico, de louco e de todo mundo um pouco. In: Guimarães, Reinaldo e TAVARES, Ricardo (orgs.). Saúde e sociedade no Brasil - anos 80. Rio de Janeiro: Relumé-Dumará/ABRASCO/IMS-UERJ, 1994. p. 171-91.

Braga Campos, Florianita. Considerações sobre o movimento de reforma dos serviços de saúde mental. In: Braga Campos, Florianita C. (org.). Psicologia e saúde repensando práticas. São Paulo: Hucitec, 1992a. p. 59-64.

O lugar da saúde mental na saúde. In: Braga Campos, Florianita (org.). Psicologia e saúde - repensando práticas. São Paulo: Hucitec, 1992b. p. 47-57. 


\section{SAÚDE MENTAL}

ano VIII, n. 2, jun/2005

Camargo Jr., Kenneth. Apresentação. In: Pinheiro, Roseni e Mattos, Ruben (orgs.). Os sentidos da integralidade. Rio de Janeiro: UERJ-IMS/ABRASCO, 2001.

CAmpos, Gastão. Reforma da reforma - repensando a saúde. São Paulo: Hucitec, 1992. CAstel, Robert. A ordem psiquiátrica: a idade de ouro do alienismo. Rio de Janeiro: Graal, 1978.

Delgado, Pedro Gabriel. As razões da tutela: psiquiatria, justiça e cidadania do louco no Brasil. Rio de Janeiro: Te Corá, 1992.

Atendimento psicossocial na metrópole: algumas questões iniciais. Cadernos do IPUB, Rio de Janeiro: UFRJ, n. 14, p. 113-22, 1999.

O tratamento a partir da reforma psiquiátrica. In: Quinet, Antonio. Psicanálise e psiquiatria: controvérsias e convergências. Rio de Janeiro: Rios Ambiciosos, 2001. p. 153-8.

Dell'Acqua, Giuseppe e Mezzina, Roberto. Resposta à crise - estratégia e intencionalidade da intervenção no serviço psiquiátrico territorial. In: DelgADo, Jaques (org.). A loucura na sala de jantar. São Paulo: Resenha, 1991. p. 53-95.

Fernandes, Maria; Scarcelli, Ianni e Costa, Eliane (orgs.). Fim de século: ainda manicômios? São Paulo: IPUSP, 1999.

FURTADO, Juarez. Responsabilização e vínculo no tratamento de pacientes cronificados: da unidade de reabilitação de moradores ao CAPS estação. In: HARARI, Ângela e VAlentini, Willians (orgs.). A reforma psiquiátrica no cotidiano. São Paulo: Hucitec, 2001. p. 37-58.

GoldBerg, Jairo. A clínica da psicose. Rio de Janeiro: Te Corá/IFB, 1996.

Jameguberry, Inês e Moscovich, David. La responsabilidad del sujeto em la psicosis. In: Pujó, Mario (org.). Las psicosis, psicoanálisis y el hospital, n. 11, p. 8-10, jun 17, 1997.

Leal, Erotildes Maria. O agente do cuidado na Reforma Psiquiátrica Brasileira: modelos de conhecimento. 1999. 260p. Tese (doutorado em Psicanálise, Psiquiatria e Saúde Mental). Universidade Federal do Rio de Janeiro - Instituto de Psiquiatria.

Lima, Antonio Carlos. Um grande cerco de paz - poder tutelar, indianidade e formação do Estado no Brasil. Petrópolis: Vozes, 1995.

Luz, Madel. Políticas de descentralização e cidadania: novas práticas de saúde no Brasil atual. In: Pinheiro, Roseni e Mattos, Ruben. (orgs.). Os sentidos da integralidade. Rio de Janeiro: UERJ-IMS/ABRASCO, 2001.

NicÁcio, Fernanda. O processo de transformação da saúde mental em Santos: desconstrução de saberes, instituições e cultura. 1994. 193p. Dissertação (mestrado em Ciências Sociais). Pontifícia Universidade Católica de São Paulo.

Offe, Claus. Problemas estruturais do Estado capitalista. Rio de Janeiro: Tempo Brasileiro, 1984.

Rotelli, F. et al. Desinstitucionalização, uma outra via - a Reforma Psiquiátrica Italiana 


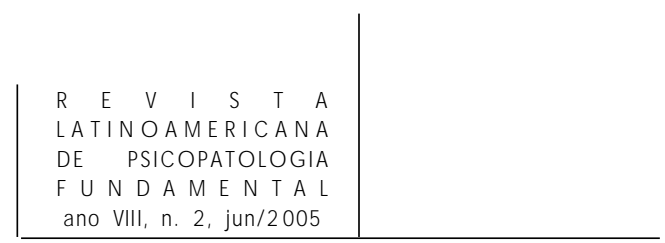

no contexto da Europa Ocidental e dos “países avançados”. In: NicÁcio, Fernanda (org). Desinstitucionalização. São Paulo: Hucitec, 1990. p. 17-59.

Russo, Jane. Os três sujeitos da psiquiatria. Cadernos do IPUB, Rio de Janeiro: UFRJ, n. 7, p. 11-21, 1997.

TenóRIo, Fernando. Psicanálise, configuração individualista de valores e ética do social. História, ciências e saúde, v. VII, n. 1, p. 117-34, mar-jun, 2000.

Reforma psiquiátrica e psicanálise: um trabalho necessário. In: FigueIREdo, Ana Cristina e Cavalcanti, Maria Tavares (orgs.). A Reforma Psiquiátrica e os desafios da desinstitucionalização. Rio de Janeiro: IPUB/CUCA, 2001. p. 69-84.

ViannA, Adriana. Limites da menoridade: tutela, família e autoridade em julgamento. 2002. 334p. Tese (Doutorado em Antropologia Social). Universidade Federal do Rio de Janeiro - Museu Nacional.

\section{Resumos}

Este texto visa delinear la relación entre saberes y políticas en el campo de la salud mental. Discursos como "recibir responsabilidad del servicio por el territorio", el "aumento de la responsabilidad del profesional por el proceso de trabajo" y la "posibilidad del sujeto advenir como responsable por su propia condición” son vehiculados por distintas disciplinas, como el psicoanálisis, la salud pública y el análisis institucional. Esos discursos se conjugan con un momento socio-histórico particular en Brasil. Se cree que la descentralización, preconizada por las políticas públicas de salud, desencadena un proceso de "transferencia de responsabilidades para unidades locales con concentración de poder en el ámbito central”.

Palabras claves: Responsabilidad, salud mental, formación profesional, politicas públicas de salud

Ce texte vise à discriminer la relation entre les savoirs et les politiques dans le champ de la santé mentale. Des propositions telles que "la prise de responsabilité du service par le territoire", "l'augmentation de la responsabilité du professionnel" et "la possibilité du sujet de devenir responsable de sa propre condition" sont propagées par différentes disciplines, comme la psychanalyse, la santé publique et l'analyse institutionnelle. Ces discours se conjuguent à un moment socio-historique particulier au Brésil. On suppose que la décentralisation proposée par les politiques publiques de santé déclenche un processus de transfert de responsabilité pour les unités locales de santé, avec une concentration de pouvoir au niveau central.

Mots clés: Responsabilité, santé mentale, formation professionnelle, politique publique de santé 
This text aims at outlining the relationship between knowledge and policies in mental health. The "shift of responsibility from service to territory", the "increase of responsibility taken by mental health professionals", and the "possibility that the subject accounts for his/her own condition" are propositions that spring from different discourses and disciplines, namely psychoanalysis, public health, and institutional analysis. Such discourses refer to a very particular social and historical moment in Brazil. It is believed that decentralization - proposed by public health policies unchains a process of "transference of responsibility to local health units but keeps the concentration of power in central level".

Key words: Responsibility, mental health, professional training, mental health policies 